\title{
INVESTIGATING CROSS CONGRUENCE BETWEEN BUTTERFLY TAXA AND ECOLOGICAL COMMUNITIES WITHIN THE FRAMEWORK OF SYSTEMATIC CONSERVATION PLANNING: A CASE STUDY FROM LESSER CAUCASUS ECOREGION OF TURKEY
}

\author{
BANU KAYA ÖZDEMIREL ${ }^{1}$ \\ ${ }^{1}$ Middle East Technical University, Department of Biological Sciences, Ankara, Turkey \\ email:banukaya00@gmail.com
}

\begin{abstract}
.
Cross congruence was investigated between butterfly taxa and ecological communities for fine spatial scale (10 $\times$ $10 \mathrm{~km}^{2}$ UTM grids) in the north-eastern part of Turkey. The study was carried out within the scope of systematic conservation planning, and thus, analyses were performed for sets of priority protected areas composed using complementarity-based site selection software Marxan. Cross congruence was subsequently examined for both species richness and ecological complementarity. Accordingly, it was observed that cross congruence between butterfly taxa and ecological communities was relatively better than the results of previous studies. Another remarkable finding of the study was that ecological communities is a more robust surrogate than butterfly taxa. Although the results are valuable for conservation studies, they highlighted that a simple surrogate-based site selection could not be adequate to represent overall biodiversity. In addition, it was understood that the weakness of congruence patterns among surrogate groups could lead to gaps in biodiversity conservation. These findings drew attention to the necessity of incorporating surrogates of distinct ecology or other surrogates like environmental parameters into conservation planning. On the other hand, this study emphasized the importance of understanding the cross congruence between surrogates for implementing conservation planning effectively.
\end{abstract}

Key words: cross congruence, ecological complementarity, Marxan, species richness, surrogates

\section{INTRODUCTION}

The full range of biodiversity cannot be determined. Detailed biodiversity inventories need funds, time, and logistics. However, lack of resources does not allow detailed biodiversity inventories. This is one of the main problems in biodiversity conservation (Lund and Rahbek 2002). Knowledge about spatial patterns of biodiversity points to where conservation efforts should be carried out (Axmacher et al. 2011). Therefore, surrogates in biodiversity conservation have become necessary (Oertli et al. 2005; Gaspar et al. 2010) since they show biodiversity hotspots. On the other hand, it is still unclear how well surrogate groups represent each other (Fattorini et al. 2011). This depends on cross congruence between surrogate groups. Cross congruence between surrogates is mostly variable depending on the scale of the sampling units (Sue et al. 2004; Fattorini et al. 2011), measurement methods, and geographic pattern. Most studies indicated high cross congruence between surrogates at coarse spatial scale $\left(\geq 10.000 \mathrm{~km}^{2}\right)$ (Lund and Rahbek 2002; van Werd and Udo de Haes 2010), i.e., in tropics (Balmford and Long 1995), in western North America (Pearson and Carroll 1999), in biodiversity hotspots (Myers et al. 2000), in WWF's ecoregions. Cross congruence of surrogates $(\leq 100$ $\mathrm{km}^{2}$ ) is, however, more critical at a fine spatial scale due to the benefits of local-scale biodiversity conservation. Unfortunately, studies indicated that cross congruence between surrogate groups is ambiguous for that scale with sometimes low or sometimes high congruence (Lund and Rahbek 2002; Kati et al. 2004; Heino et al. 2009). Therefore, a consensus has not been achieved on which surrogate groups indicate better cross congruence for local-scale conservation planning (Heino et al. 2009). Cross congruence of surrogates has been investigated in some regions for various spatial scales. However, there are still some gaps in cross congruence studies of surrogates, and more studies are required, especially in the regions where rich biodiversity is found and urgent conservation strategies are needed (van Weerd and Udo de Haes 2010). Turkey is one of these regions. It is very attractive with its rich biodiversity and high endemism rate and is thus important globally (Ciplak 2008; Fattoroni et al. 2011). Unfortunately, the majority of biodiversity is under serious threat. At the same time, studies on investigating the cross congruence of surrogates are highly inadequate for the region. The studies conducted by Fattorini et al. $(2011,2012)$ on arthropods of Turkey have been the only studies that investigated cross congruence for 
(A)

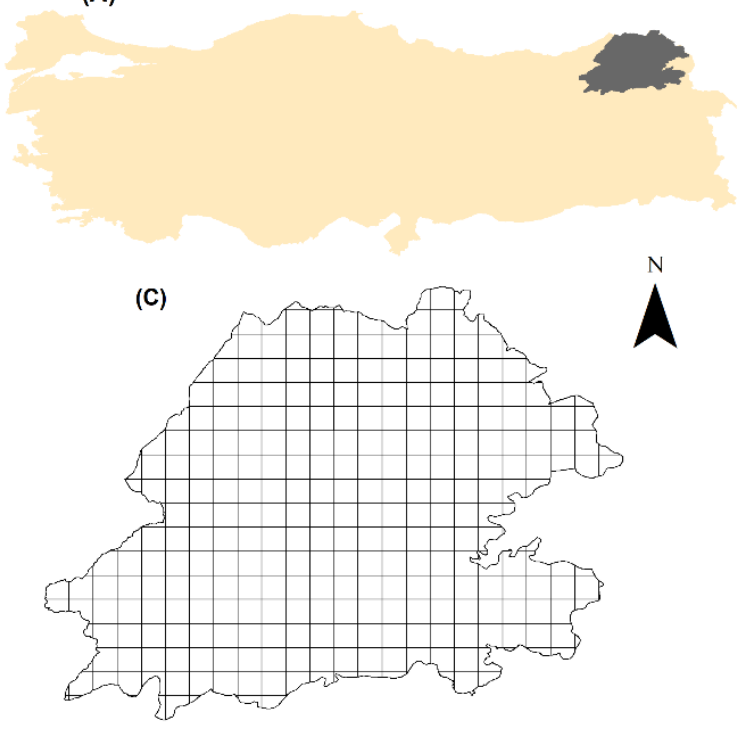

(B)

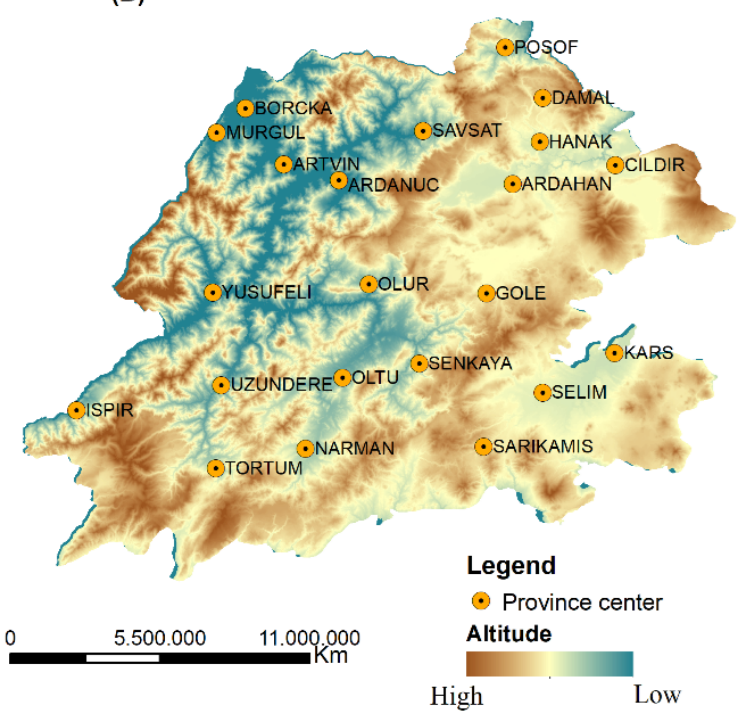

Figure 1: A- Location of the study area, B- study area, distribution of provinces and altitude, C- $10 \mathrm{X} 10 \mathrm{~km}^{2} \mathrm{UTM}$ (working) grids (Kaya Özdemirel 2013).

surrogates in Turkey. This is a significant deficiency because studies on cross congruence reveal relationships between surrogates and, thus, provide input for conservation planning (Margules and Pressey 2000; van Weerd and Udo de Haes 2010).

In this study, cross congruence was aimed to investigate between butterfly taxa and the ecological communities at a local spatial scale in the Lesser Caucasus Ecoregion of Turkey $\left(10 \times 10 \mathrm{~km}^{2}\right)$. The area is a part of the global 200 Ecoregion named as Caucasus-Anatolian-Hyrcanian Temperate Forests on WWF's Global 200 list of the world's most important areas (WWF International 2007), and it is also shown among the Planet's 25 most diverse and endemic hotspots by Conservation International (Wilson 2006). The study area has, in brief, high conservation priority on a global scale, and therefore, conserving the biodiversity of the area is critical. In the study, the area was assessed within the scope of the conservation planning approach. Cross congruence between butterfly taxa and ecological communities was analyzed for species richness and complementarity accordingly. Species richness is a valuable and widely used measurement for biodiversity assessments (van Weerd and Udo de Haes 2010). It is, however, not sufficient alone for conservation targets of biodiversity (Oertli et al. 2005). It does not give any insight into the identity of species ( $\mathrm{Su}$ et al. 2004). On the other hand, the Complementarity principle considers rarity and irreplaceability (Margules and Pressey 2000; Ferrier et al. 2000; Williams et al.
2006; Carwardine et al. 2007) and, consequently, enables conservation of endemic, threatened, and globally important species. Therefore, the study results can provide information and present new insight into biodiversity conservation efforts of the study area and thus, guide local managers for future land planning and development of conservation strategies. On the other hand, results indicated some of the deficiencies of the surrogacy approach. A general conclusion was drawn accordingly to emphasize the constraint of the surrogate applications, and also, some suggestions were made.

\section{Materials and Methods}

\subsection{Study area}

The study area is in the north-eastern part of Turkey and encompasses approximately $35000 \mathrm{~km}^{2}$ (Figure 1A). The area covers all of Ardahan, southern and eastern Artvin, north-eastern Erzurum, and parts of Kars, but excludes the northern slopes of the Kaçkar Mountains, coastal Artvin, and the Aras valley because these parts are biogeographically and climatically different from the rest of the area (Figure 1B). The area is quite remarkable with its geographic features. It is mainly characterized by high mountainous, broad plateaus, and deep valleys and has an altitude range of roughly 50 to $3900 \mathrm{~m}$ (Figure 1B). This rugged topography determines different ecological units of the area. The mountains divide the region into two primary ecological sub-units: humid 
temperate forests and dry high mountain steppe-alpine meadows, while the deep valleys are dominated by Mediterranean vegetation, including typical Mediterranean maquis and stone pine (Pinus pinea). This diverse landscape, in conjunction with varying climate and evolutionary history, results in high taxonomic diversity, high endemism rate, and various relict organisms. For example, the area demonstrates high plant diversity and endemism and hosts many large and small mammals. On the other hand, one of the most important bird migratory routes on Earth passes over the lesser Caucasus region. Therefore, several bird species inhabit the area. Moreover, the study area includes many endangered, rare, or endemic reptile, amphibian, and butterfly species.

\subsection{Data included in the analyses}

The study area was projected using Universal Transverse Mercator (UTM) north zone 37 and divided into 336 mappings (UTM) grids of $10 \times 10 \mathrm{~km}^{2}$ for analysis (Figure 1C). All the biological data used in the study were gathered according to the scale of the UTM grids. Two different surrogate groups that are butterflies and ecological communities, were included in the analyses. Butterfly data were obtained from "Die Tagfalter der Türkei unter besonderer Berücksichtigung der angrenzenden Länder" (Hesselbarth et al. 1995) (The Butterflies of Turkey with special attention to the adjacent countries). It is the most detailed study on butterflies and their distribution in Turkey. In the reference book, the butterfly data was arranged as $10 \times 10 \mathrm{~km}^{2}$ grids. The data was therefore easily adjusted to the current study. 2833 occurrence records of 251 butterfly species were colligated for the study (Table 1) and included in the analyses. The ecological communities map was composed using Corine Land Cover data, digital elevation model (dem), slope, 1/ 100.000 forest layouts, and 1/ 25.000 forest management layouts. The main input layer of the ecological communities map was Corine Land Cover data (CLC). In the study, the CLC data released in 2006 was used. It was produced by the European Environment Agency (EEA) and its member countries. Its original resolution is $1 / 100.000$, and the standard CLC nomenclature includes 44 land cover classes. However, the CLC data layer of the study area contains 21 land cover classes. The layer was processed using the co-variables mentioned above considering vegetation's structural characteristics, topographic features, dominant species, and sub-ecoregions. Consequently, an ecological communities layer including 6204 records of 32 distinct ecological communities was produced (Table 1 ). The map was then overlaid with $10 \times 10 \mathrm{~km}^{2}$ UTM grids to adjust the resolution with butterfly species data.

\subsection{Analyses to examine cross congruence}

Cross congruence was examined between two surrogate groups (i.e., butterfly taxa and ecological communities) using sets of priority protected areas. Marxan site selection software was used to detect priority protected areas. Cross congruence of butter-

Table 1: Examining cross congruence in minimum area sets of surrogates using percent representation, jaccard coefficient, richness correlation and complementary correlation

\begin{tabular}{lcc}
\hline \multicolumn{1}{c}{$\begin{array}{c}\text { Cross congruence } \\
\text { (area selection based on) }\end{array}$} & Butterfly & Ecological communities \\
Inventories of conservation feature & $251 \mathrm{sp}$. & $32 \mathrm{comm}$. \\
Min number of sites & $2833 \mathrm{rec}$. & $6204 \mathrm{rec}$. \\
Percent representation & 19 & 9 \\
Butterfly & 0.94 & 0.79 \\
Ecological communities & 0.67 & 1 \\
Jaccard coefficient & & 18.51 \\
Butterfly & - & - \\
Ecological communities & 18.51 & $0.63^{* *}$ \\
Richness correlation & & $\mathbf{0 . 0 0 1 )}$ \\
Butterfly & - & - \\
Ecological communities & 0.49 & \\
Complementarity correlation & $\mathbf{0 . 0 5 )}$ & $0.57^{*}$ \\
Butterfly & & $\mathbf{0}$ \\
Ecological communities & - & - \\
\hline
\end{tabular}


fly taxa and ecological communities were measured within selected area sets. Marxan selects priority protected areas by meeting user-defined conservation targets. The software firstly achieves design of the priority protected areas with at least possible cost (McDonnell et al. 2002), i.e., representing the maximum number of biological features within a minimum number of areas or minimum size and secondly, it composes complementarity priority protected areas, i.e., protected areas network includes compositionally different areas (Vane-Wright et al. 1991; Pressey et al. 1993). It uses a mathematical simulated annealing algorithm to achieve the selection of priority protected areas. The algorithm starts the simulations with a set of randomly selected planning units, and then planning units are included or excluded from the set in a series of iterations by comparing the cost of each new set with that of the previous set. The procedure continues until an equilibrium solution is achieved, meeting conservation targets in the smallest number of planning units (Cook and Auster 2005; Zielinski et al. 2006).

In the study, conservation targets were firstly given for each species and ecological community. The conservation target is the amount of each conservation feature to be included within the priority protected areas. Conservation targets were defined using species and communities importance scores. These scores were produced according to the threat categories, rarity, and endemism of the related conservation features; thus, higher conservation targets were given for the species and ecological communities of particular conservation concerns. Accordingly, while one representation was applied as a conservation target of common species in priority protected areas, two or more representations were assigned for endemic, threatened, and rare species. Ecological communities were likewise assessed according to rarity, uniqueness, and threats. Consequently, conservation targets between 10 and $50 \%$ have been used, considering the conservation requirement of the ecological communities. Moreover, conservation features of high importance scores were appointed with higher species penalty factors; thus, Marxan has put more effort into meeting conservation targets of those features (Game and Grantham 2008). This procedure provides that species or communities of high conservation value are less likely excluded from the priority protected areas. In addition, it was assumed that threats to biodiversity increase the cost of biodiversity conservation. Therefore, cost values were determined and assigned for each planning unit based on the threats for the planning unit. Cost values enable the measurement of conservation costs of the selected priority protected areas. With this approach, planning units increasing the conservation cost were not included in the priority protected areas. However, some costly planning units may host special conservation features, and these planning units had to be included in the priority protected areas. In such cases, planning unit status was used. Planning unit status determines whether the planning unit fixed in or out to the priority protected areas (Game and Grantham 2008), and thus, mentioned planning units were included in the priority protected areas. Marxan was run with these settings and 100 repeated runs with 1000 iterations for each.

Two different sets of priority protected areas were composed for each surrogate group (i.e., butterfly taxa and ecological communities). Initially, a set of the minimum number of priority protected areas was identified, and cross congruence was examined in these area sets using four different measurements. Representation was firstly calculated to understand how effectively the selected area set represents the other surrogate group. Representation value was calculated as the percentage of a total number of conservation features (butterfly species or ecological communities). Secondly, the overlap between each surrogate group's minimum number area set was measured using the Jaccard coefficient (Jack. C) (van Jaarsveld et al. 1998; Warman et al. 2004). Jaccard coefficient is a similarity coefficient and calculates percentage overlap among sets of priority protected areas (Formula 1).

Jacc. $C=\left[\frac{\text { number of shared sites }}{\text { additional sites for taxon } A+\text { additionla sites for taxon } B}\right] \times 100$

Thirdly, Spearman's rank correlation (Spearman's rho, $\rho$ ) was applied to investigate richness correlations among minimum number priority protected areas set of each surrogate group. Richness was calculated as the total number of conservation features (butterfly species or ecological communities) within each surrogate group's minimum number area set. Lastly, cross congruence between butterfly taxa and ecological communities was analyzed for complementarity. Euclidian distance matrices were produced for this purpose. Euclidian distance measures similarities between pairs of sites and thus indicate compositional distinctiveness within two sites. This measurement is equal to the complementarity prin- 
ciple. Distance matrices were assessed applying the mantel correlation test with 1000 permutations (Sue et al. 2004; Oertli et al. 2005; Fattorini et al. 2011). Mantel test evaluates the hypothesis that assumes no relationship between two matrices (Sue et al. 2004). Thus, this test indicates how efficiently the minimum number of priority protected areas of a surrogate group complement other groups.

In the second part, sets of priority protected areas containing an equal number of planning units $(n=19)$ were detected for each surrogate group, i.e., $n=19$ was the optimum number of priority areas selected using all data of two surrogates. Then, the cross congruence of surrogate groups was examined for equal number area sets using three measurements. First, standardized complementarity scores were calculated for each surrogate group in the equal number priority protected area sets. This score examines the cross congruence of surrogates in complementarity (van Weerd and Udo de Haes 2010). It is the total complementarity of a grid cell and was calculated using Euclidean distance matrices. Correlations of these scores were afterward evaluated applying Spearman's rank correlation. Second, cumulative complementarity scores of surrogate groups were calculated, and curves were composed as cumulative complementarity scores versus a number of sites. These curves indicated which surrogate group achieves better complementarity for others. Finally, an accumulation curve was generated as the number of sites versus cumulative species representation. The curve is an appropriate way to indicate how effectively an equal area set of a surrogate group can represent other surrogate species. It also enables comparing the efficacy of equal area sets of surrogates and indicates how better their representation is than random areas composed with 1000 permutations.

\section{RESULTS}

Cross congruence between butterfly taxa and ecological communities was examined in both minimum and the equal number of priority-protected areas. Marxan identified 19 and 9 minimum number priority protected areas for butterflies and ecological communities, respectively (Table 1 ). Cross congruence of surrogates was measured using percent representation, Jaccard coefficient, richness correlation, and complementarity correlation in the minimum priority protected areas. Accordingly, results indicated that the minimum area set of the ecological communities is better at representing butterfly taxa.
While the percent representation of butterfly taxa in the minimum area set of ecological communities was 0.79 , the percent representation of the ecological communities in the minimum area set of butterfly taxa was 0.67 (Table 1). The remarkable result is that the minimum area set of butterfly taxa achieved 0.94 representation for its species (Table 1). This means that some of the butterfly species cannot be included in the minimum number of priority protected areas of butterfly taxa. On the other hand, the percent representation of the ecological communities in the minimum number priority protected areas of ecological communities was 1 . That is, all ecological communities were included in the minimum area set of the ecological communities.

As in previous studies (Van Jaarsveld et al. 1998), a little overlap was found between sets of the minimum number priority protected areas (Table 1). According to the Jaccard coefficient, the overlap was just $18.51 \%$ between the minimum area set of ecological communities and butterfly taxa. (Table 1). Moreover, a strong correlation in richness was not achieved between two surrogate groups in the minimum area set of butterfly taxa. Spearman's rank correlation coefficient was $(\rho=0.49)$ between ecological communities and butterfly taxa for the minimum area set of butterfly taxa, and it was not a statistically significant correlation (> $\mathbf{0 . 0 5}$, Table 1$)$. On the other hand, a statistically significant correlation coefficient was observed between two surrogate groups in the minimum area set of ecological communities for richness $\left(\rho=0.63^{*},<\mathbf{0 . 0 0 1}\right.$, Table 1$)$. Likewise, there was a statistically significant complementarity correlation between ecological communities and butterflies in the minimum area set of the ecological communities $\left(r=0.57^{*},<\mathbf{0 . 0 5}\right.$, Table 1$)$. However, complementarity correlation was not statistically significant between two surrogate groups in the minimum area set of butterfly taxa $(r=0.32,<\mathbf{0 . 0 5}$, Table 1). These findings indicated that the ecological communities are more robust at representing butterfly taxa in the minimum number of priority protected areas (Table 1).

Evaluation of cross congruence in the equal area set of surrogate groups was performed using standardized complementary, cumulative complementarity, and cumulative species representation. Results showed that although there is no strong correlation in the standardized complementarity scores, the correlation coefficients are statistically significant. Accordingly, it can be said that the correlation of com- 


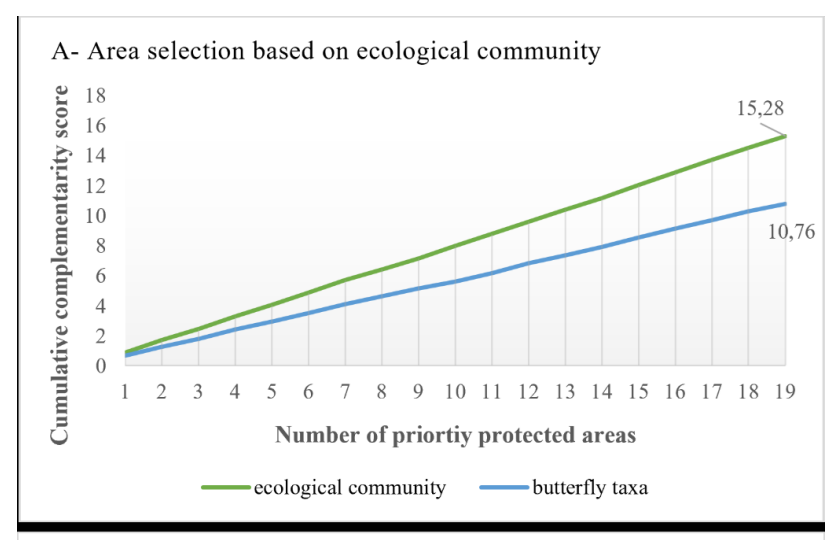

B- Area selection based on butterfly taxa

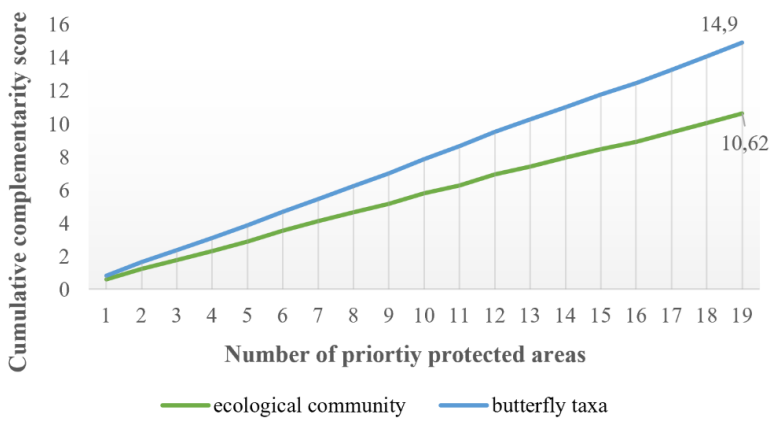

Figure 2: Efficacy of surrogates according to the cumulative complementarity scores in equal area sets of A- ecological communities and B- butterfly taxa.

plementarity was relatively high between ecological communities and butterfly taxa in both equal-area sets of butterfly taxa and ecological communities ( $\rho=0.51^{*}$ and $\rho=0.57^{*}$ respectively, Table 2 ). The equal-area set of priority protected areas include 19 priority protected areas. The number of priority protected areas is greater in the equal area sets than in the minimum area sets. It can therefore be concluded that as the number of priority areas increases, complementarity increases. The efficacy of surrogates for the cumulative complementarity scores was evaluated by composing graphs as the number of areas versus cumulative complementarity (Figure 2). Accordingly, it was seen that equal area sets of the surrogate groups could not provide the complementarity to the other surrogate group that they provide for themselves (Figure 2). Figure 2 indicated that the cumulative complementarity score of the ecological communities (15.28) in their own equal-area set is higher than the cumulative complementarity score of butterfly taxa (10.46). Similarly, the cumulative complementarity score of butterflies in their own equal-area set is higher (14.9), while the cumulative complementarity score of the ecological communities is lower (10.62) in the equal area set of butter-

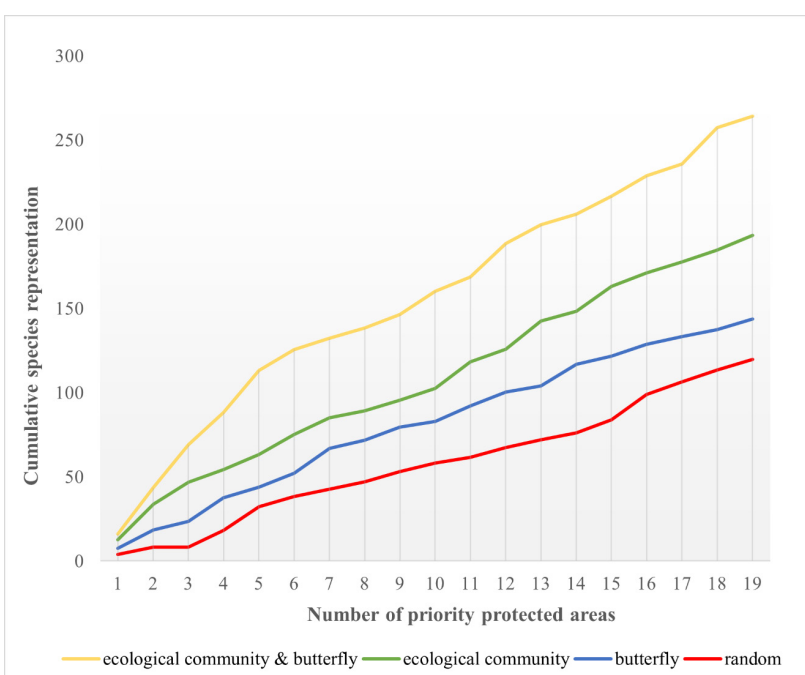

Figure 3. Comparison among surrogate groups according to the cumulative species representation of equal area sets.

flies (Figure 2). Species representation's accumulation curve also highlighted the efficiency of surrogate groups in equal area sets. Accordingly, an equal area set of the ecological communities had a higher species representation than the equal-area set of the butterfly taxa (Figure 3). However, not surprisingly, an equal-area set composed using two surrogate groups indicated nearly two times better cumulative species representation than the equal-area set of the ecological communities (Figure 3). Moreover, equal-area sets of butterfly taxa had slightly better cumulative species representation than random selection (Figure 3).

\section{Discussion ANd Conclusion}

In the study, Marxan site selection software was used to design both minimum and equal number priority protected areas sets to examine the efficiency of surrogate groups for the Lesser Caucasus Ecoregion.

Table 2. Examining cross congruence in equal area sets of surrogate groups evaluating correlation between standardized complementarity scores.

\section{Cross congruence (area selection based on) \\ Butterfly \\ Ecological communities}

Correlation between std. complementarity scores

\begin{tabular}{lcc} 
Butterfly & & $0.57^{*}$ \\
Ecological communities & $0.51^{*}$ & $(<\mathbf{0 . 0 5})$ \\
& $(<\mathbf{0 . 0 5})$ & \\
\hline
\end{tabular}

Note: "rec." = number of records, * significance level of $5 \%(\mathrm{P}<0.05),{ }^{* *}$ significance level of $1 \%(\mathrm{P}<0.001)$. 
The software achieved selection of priority protected area sets, meeting conservation targets of surrogate groups. It also enabled the development of cost-effective and more efficient area sets for the study area. In addition, the software provided easy implementation with its user-friendly interface. Consequently, outputs of the study presented slightly better congruence pattern between surrogate groups than the previous studies that have already been reported low or non-congruent patterns between most of the surrogate groups (Gaston 2000; Negi and Gadgil 2002; Ricketts et al. 2002; Juutinen and Monkkonen 2004; Posa and Sodhi 2006; Nöske et al. 2008; van Weerd and Udo de Haes 2010; Axmacher et al. 2009; 2011). Accordingly, Species representation and complementarity scores of butterflies obtained in priority area sets of the ecological communities were better than the scores of the ecological communities calculated in the area sets of butterfly taxa. These results indicated the robustness of ecological communities as surrogates. As known, an ecological community is a group or association including two or more species that interact with each other through the food chain and meet the ecological requirements of species that inhabit it. This means that an ecological community can represent lots of species in a protected area system. It is therefore highly possible for ecological communities to be good surrogates for conservation planning. Briefly, incorporating ecological communities into conservation planning as surrogate provides both a more adequate representation of conservation features and presents a cost-effective solution due to easy accessibility.

Moreover, the study results indicated that single surrogate-based site selection provides low species representation while two surrogate-based site selections achieve higher species representation. Therefore, using as many as surrogate groups in conservation area planning is the most effective way to adequately protect the full range of biodiversity. However, it is mostly not possible because of the fund and logistic requirements. The wise solution, in that case, is to incorporate surrogate groups with distinct spatial distribution and ecological requirements into conservation area planning (Fattaroni et al. 2011). Using such surrogates in area planning generate compositional distinctiveness, thus increase species representation and complementarity within the protected area system. Complementarity is an important principle to design more efficient and cost-effective biodiversity conservation areas since it aims to protect the maximum number of conservation features within a minimum number of areas. However, it requires reliable and consistent surrogate data. Otherwise, biodiversity conservation cannot be fulfilled effectively due to the gaps in biodiversity representations. It seems that although it has many limitations, biological surrogates are needed for conservation area planning. Alternatively, environmental information like soil, water components, climate, and topographic features may be included in conservation planning as surrogates. Some studies have been recently investigated the relationship between biological surrogates and some environmental parameters (e.g., Heino et al. 2009; Schouten et al. 2010; Axmacher et al. 2011; Hassall et al. 2011; Vera et al. 2011). Some of the results are very encouraging, but further studies are needed before integrating them into conservation planning.

\section{ACKNOWLEDGEMENTS}

Butterfly data was arranged from "Die Tagfalter der Türkei unter besonderer Berücksichtigung der angrenzenden Länder". It was published by G. Hesselbarth, H. Van Oorschot and S. Wagener. Corine land cover data was obtained from Pan-European component of Copernicus that is coordinated by the European Environment Agency (EEA). The data freely available. Site selections were done using Marxan conservation planning software developed at the University of Queensland.

\section{REFERENCES}

Axmacher, J. C., Brehm, G., Hemp, A., Tünte, H., Lyaruu, H. V. M., Müller-Hohenstein, K. Fiedle,r K. (2009) Determinants of diversity in afrotropical herbivorous insects (Lepidoptera: Geometridae): plant diversity, vegetation structure or abiotic factors? Journal of Biogeography, 36, 337-349, doi:10.1111/j.1365-2699.2008. 01997.x.

Axmacher, J. C., Liu, Y., Wang, C., Li, L., Yu, Z. (2011) Spatial $\alpha$-diversity patterns of diverse insect taxa in Northern China: Lessons for biodiversity conservation. Biological Conservation, 144, 2362-2368, doi: 10.1016/j.biocon.2011.06.016.

Balmford, A., Long, A. (1995) Across-country analyses of biodiversity congruence and current conservation effort in the tropics. Conservation Biology, 9, 1539-1547, doi: 10.1046/j.15231739.1995. 09061539.x. 
Carwardine, J., Rochester, W. A., Richardson, K. S., Williams, K. J., Pressey, R. L., Possingham, H. P. (2007) Conservation planning with irreplaceability: does the method matter? Biodiversity and Conservation, 16, 245-258, doi: 10.1007/ s10531-006-9055-4.

Ciplak, B. (2008) The analogy between interglacial and global warming for the glacial relicts in a refugium: a biogeographic perspective for conservation of Anatolian Orthoptera. In: Fattorini, S. (Ed.), Insect Ecology and Conservation, Research Signpost, Kerala, pp. 135-163.

Cook, R. R., Auster, P. J. (2005) Use of simulated annealing for identifying essential fish habitat in a multispecies context. Conservation Biology, 19, 876-886, doi: 10.1111/j.1523-1739.2005. 00613.x.

Fattorini, S., Dennis, R. L. H., Cook, L. M. (2011) Conserving organisms over large regions require multi-taxa indicators: One taxon's diversity-vacant area is another taxon's diversity zone. Biological Conservation, 144, 1690-1701, doi: 10.1016/j.biocon.2011.03.002.

Fattorini, S., Dennis, R. L. H., Cook, L. M. (2012) Use of Cross-Taxon Congruence for Hotspot Identification at a Regional Scale. PLoS ONE, 7(6), e40018, doi: 10.1371/journal.pone.0040018.

Ferrier, S., Pressey, R. L., Barret, T. W. (2000) A new predictor of the irreplaceability of areas for achieving conservation goals, its application to real-world planning, and a research agenda for further refinement. Biological Conservation, 93, 303-325, doi: 10.1016/S0006-3207(99)00149-4.

Gaston, K. J. (2000) Global patterns in biodiversity. Nature, 405, 220-227, doi: 10.1038/35012228.

Hassal, C., Hollinshead, J., Hull, A. (2011) Environmental correlates of plant and invertebrate species richness in ponds. Biodiversity and Conservation, 20, 3189-3222, doi: 10.1007/s10531011-0142-9.

Heino, J., Tolonen, K. T., Kotonen, J., Paasivirta, L. (2009) Indicator groups and congruence of assemblage similarity, species richness and environmental relationship in littoral macroinvertebrates. Biodiversity and Conservation, 18, 3085-3098, doi: 10. 1007/s10531-009-9626-2.

Hesselbart, G., Van Oorschot, H., Wagener, S. (1995) Die Tagfalter der Türkei, under Berücksichtigung der angrenzenden Länder, Dem Volk der Türkei.
Juutinen, A., Monkkonen, M. (2004) Testing alternative indicators for biodiversity conservation in old-growth boreal forest: ecology and economics. Ecological Economics, 50, 35-48, doi: 10.1016/j.ecolecon.2004.02.006.

Lund, M. P., Rahbek, C. (2002) Cross-taxon congruence in complementarity and conservation of temperate biodiversity. Animal Conservation, 5, 163-171, doi: 10.1017/S1367943002002226.

Margules, C. R., Pressey, R. L. (2000) Systematic conservation planning. Nature, 405, 243-253, doi: 10.1038/35012251.

McDonnell, M. D., Possingham, H. P., Ball, I.R., Cousins, E. A. (2002) Mathematical Methods for Spatially Cohesive Reserve Design. Environmental Modelling and Assessment, 7, 107-114, doi: 10.1023/A:1015649716111.

Myers, N., Mittermeier, R. A., Mittermeier, C. G., da Fonseca, G. A. B., Kent, J. (2000) Biodiversity hotspots for conservation priorities. Nature, 403, 853-858, doi: 10.1038/35002501.

Negi, H. R., Gadgil, M. (2002) Cross-taxon surrogacy of biodiversity in the Indian Garhwal Himalaya. Biological Conservation, 105, 143-155, doi: 10.1016/S0006-3207(01)00158-6.

Nöske, N. M., Hilt, N., Werner, F. A., Brehm, G., Fiedler, K., Sipman, H. J. M., Gradstein, S. R. (2008) Disturbance effects on diversity of epiphytes and moths in a montane forest in Ecuador. Basic and Applied Ecology, 9, 4-12, doi: 10.1016/j.baae.2007.06.014.

Oertli, S., Müller, A., Steiner, D., Breitenstein, A., Dorn, S. (2005) Cross-taxon congruence of species diversity and communities similarity among three insect taxa in a mosaic landscape. Biological Conservation, 126, 195-205, doi:

Pearson, D. L., Carroll, S. S. (1999) The influence of spatial scale on cross-taxon congruence patterns and prediction accuracy of species richness. Journal of Biogeography, 26(5), 1079-1090, doi: 10.1046/j.1365-2699.1999. 00337.x.

Posa, M. R. C., Sodhi, N. S. (2006) Effects of anthropogenic land use on forest birds and butterflies in Subic Bay, Philippines. Biological Conservation, 129, 256-270, doi: 10.1016/j.biocon.2005.10.041.

Pressey, R. L., Humphries, C. J., Margules, C. R., Vane-Wright, R. I., Williams, P. H. (1993) Beyond opportunism: key principles for systematic reserve selection. Trends in Ecology \& Evolution, 8, 124-128, doi: 10.1016/0169-5347(93)90023-I. 
Schouten, M. A., Barendregt, A., Verweij, P. A., Kalkman, V. J., Kleukers, R. M. J. C., Lenders, H. J. R., Siebel, H. N. (2010) Defining hotspots of characteristic species for multiple taxonomic groups in the Netherlands. Biodiversity and Conservation, 19, 2517-2536, doi: 10.1007/s10531010-9857-2.

Sue, J. C., Debinski, D. M., Jakubauskas, M. E., Kindscher, K. (2004) Beyond species richness: Communities similarity as measure of cross-taxon congruence for coarse-filter conservation. Conservation Biology, 18, 167-173, doi: 10.1111/j.1523-1739.2004. 00337.x.

Ricketts, T. H., Daily, G. C., Ehrlich, P. R. (2002) Does butterfly diversity predict moth diversity? Testing a popular indicator taxon at local scales. Biological Conservation, 103, 361-370, doi: 10.1016/S0006-3207(01)00147-1.

Van Jaarsveld, A. S., Freitag, S., Chown, S. L., Muller, C., Koch, S., Hull, H., Bellamy, C., Krüger, M., Endrödy-Younga, S., Mansell, M. W., Scholtz, C. H. (1998) Biodiversity Assessment and Conservation Strategies. Science, 279, 2106-2108, doi: 10.1126/science.279.5359.2106.

Van Weerd, M., Udo de Haes, H. A. (2010) Cross-taxon congruence in tree, bird and bat species distributions at a moderate spatial scale across four tropical forest types in the Philippines. Biodiversity and Conservation, 19, 3393-3411, doi: 10.1007/s10531-010-9902-1.

Vane-Wright, R. I., Humphries, C. J., Williams, P. H. (1991) What to protect- systematic and the agony of choice. Biological Conservation, 55, 235-254, doi: 10.1016/0006-3207(91)90030-D.
Vera, P., Sasa, M., Encobo, S. I., Barba, E., Belda, E. J., Monro's, J. S. (2011) Land use and biodiversity congruences at local scale: applications to conservation strategies. Biodiversity and Conservation, 20, 1287-1317, doi: 10.1007/s10531011-0028-x.

Warman, L. D., Forsyth, D. M., Sinclair, A. R. E., Freemark, K., Moore, H. D., Barrett, T. W., Pressey, R. L., White, D. (2004) Species distributions, surrogacy, and important conservation regions in Canada. Ecology Letters, 7, 374-379, doi: 10.1111/j.1461-0248.2004. 00590.x.

Wilson, A., McBride, M., Bode, M., Possingham, H. P. (2006) Prioritising Global Conservation Efforts. Nature, 40, 337-340.

Williams, P. H., Burgess, N. D., Rahbek, C. (2000) Flagship species ecological complementarity and conserving the diversity of mammals and birds in sub-Saharan Africa. Animal Conservation, 3, 249-260, doi: 10.1111/j.1469-1795. 2000.tb00110. x.

Williams, P., Faith, D., Manne, L., Sechrest, W., Preston, C. (2006) Complementarity analysis: mapping the performance of surrogates for biodiversity. Biological Conservation, 128, 253-264, doi: 10.1016/j.biocon.2005.09.047.

Zielinski, W.J., Carroll, C., Dunk, J. R. (2006) Using landscape suitability models to reconcile conservation planning for two key forest predators. Biological Conservation, 133, 409-430, doi: 10.1016/j.biocon.2006.07.003. 